\title{
SEDNA - Sistema Emergencial para Desastres Naturais
}

\author{
Yuri Marinho Olivatti, André Kurt Amann Pereira, Rodrigo Filev Maia ${ }^{1}$ \\ ${ }^{1}$ Centro Universitário FEI (FEI) - São Bernardo do Campo - SP - Brazil \\ yuri_olivatti@hotmail.com, \{kpereira,rfilev\}@fei.edu.br
}

\begin{abstract}
With the population growth in large urban centers, the occupation of areas at risk of natural disasters is constantly growing and thus making the work for evacuation in emergency times more and more complex. Currently, one of the most widespread mechanisms of communication are cellular mobile devices. This paper proposes using mathematical models to identify the possibility of a risk occur and alert, through a smartphone application, the population in the risk area and designate a safe place for evacuation. The expected result of this work is that the sensors at the risk area and the model utilized indicate potential natural disaster occurrences and that this information may be sufficient to save the local population.
\end{abstract}

Resumo. Com o crescimento populacional em grandes polos urbanos a ocupação de áreas com risco de desastres naturais cresce constantemente, tornando o trabalho para evacuação, em momentos emergenciais, cada vez mais complexo. Atualmente, um dos dispositivos de comunicação mais difundidos são os celulares. Este trabalho propõe, utilizando modelos matemáticos, identificar a possibilidade de uma situação de risco ocorrer e acionar, por meio de um aplicativo móvel, a população que se encontra na área de risco e indicar uma área segura para evacuação. Espera-se, com o modelo utilizado, identificar potenciais ocorrências de desastres naturais $e$ que estas informações possam ser suficientes para salvar a população local.

\section{Introdução}

\subsection{Revisão Bibliográfica}

Muitos casos de mortes e perdas materiais devido a catástrofes naturais são registrados anualmente no Brasil. Segundo Collins (2004), mais de 29 milhões de brasileiros residem em áreas suscetíveis às inundações e 100 pessoas são vitimadas anualmente no Brasil. Esses números são decorrentes do crescimento populacional não planejado, resultando em moradias em áreas impróprias. Outras catástrofes que afetam a maioria das regiões brasileiras são as de deslizamentos de encosta. O processo de erosão e os deslizamentos, juntos à ação humana, estão constantemente causando a alteração da superfície terrestre. Esses eventos estão em contínuo aumento no Brasil, principalmente nas regiões urbanas, construções irregulares, e são responsáveis por grandes acidentes, causando perdas materiais e de vidas (Brito, 2013).

Estima-se que no mundo nos anos entre 1970 a 2012, os desastres naturais causaram cerca de 1,94 milhões de mortes e danos econômicos de 2,3 trilhões de dólares globalmente, onde na América do Sul foram mais de 50 mil vidas perdidas. (OMM, 2014). 
Muitas regiões não possuem monitoramento e métodos de evacuação dessas catástrofes, ou são ineficazes. Mesmo em grandes cidades é possível encontrar sistemas bem consolidados para mapeamento de regiões de risco, porém poucas soluções de monitoramento e evacuação são encontradas. Atualmente, os alertas que são enviados para a população são realizados por alguns métodos comuns entre organizações, onde o principal utilizado no Brasil é o das sirenes. Elas emitem um som para que a população da região evacue a área; entretanto, foi identificado pela Defesa Civil do estado do Rio de Janeiro que apenas $10 \%$ da população atende as sirenes de evacuação (Gomide, 2013).

A Defesa Civil é um conjunto de órgãos e entidades, públicos e privados, de ordem municipal a nacional, que visam à redução de desastres, a diminuição da ocorrência dos mesmos e seus efeitos. O trabalho do Sistema Nacional de Defesa Civil (SNDC) é garantir a prevenção de desastres naturais ou provocados pelo homem, com programas e planos para proteger a população e minimizar danos no caso de ocorrências, alertando, dando assistência e reabilitando pessoas, e recuperando as áreas deterioradas. Um importante trabalho é o de monitoração: prevendo-se um desastre natural a partir das condições de uma determinada região, é possível evacuar a população de forma organizada e evitar danos físicos e mortes. Esse monitoramento normalmente acontece com especialistas observando as condições das áreas de risco e prevendo de forma subjetiva sua ocorrência, por exemplo, durante uma forte chuva. Porém, o monitoramento também pode ocorrer de forma determinística, através de modelos matemáticos e uma série de parâmetros obtidos da região (Nelson, 2001).

Diante dessa situação, onde o monitoramento das regiões de risco e a evacuação através de sirenes se mostraram muitas vezes ineficazes, este projeto tem como proposta a obtenção de dados através de sensores e sua utilização em modelos matemáticos/geomorfológicos a fim de perceber e alertar a população de possíveis desastres naturais, de forma intuitiva e com amplo alcance, através de um aplicativo móvel.

A obtenção dos dados para monitoração das áreas é possível através de sensores específicos. Instalados apropriadamente, poderão coletar dados referente ao solo, clima, nível de água, entre outros parâmetros, para monitoração em tempo real e aplicação dos modelos matemáticos. Os sensores podem comparar seus dados para detectar movimentações no solo e quais áreas sofreram maior variação, como funcionam alguns sistemas de predição de deslizamentos (Terzis, et al. 2006), ou enviar dados a uma central, que os usará como parâmetros de entrada para algum modelo matemático de previsão de deslizamentos, como o SHALSTAB (Ramos, et al. 2002). O índice de criticidade de ocorrência do desastre e os dados medidos da região possibilitarão ao operador do órgão responsável pelo monitoramento observar as alterações e identificar se será necessário emitir um alerta à população.

\subsection{Objetivo}

O objetivo geral deste projeto é monitorar áreas de risco através de sensores e indicar o potencial risco de deslizamentos de terra e inundação, utilizando modelos matemáticos de avaliação em tempo real do estado do solo e índices pluviométricos, permitindo a evacuação das pessoas em risco. 
Pretende-se oferecer a análise em tempo real do risco em que as regiões monitoradas se encontram, fornecendo medições de umidade do solo e respectivos índices de estabilidade. Também se espera agilizar o processo de evacuação, através de um aplicativo para dispositivos móveis para a população, que indicará os locais seguros para fuga tendo como base a indicação dos centros de gerenciamento de emergências.

\section{Modelos Geomorfológicos}

Um modelo matemático geomorfológico é um modelo com aplicações na análise de terrenos ou relevos com diversos objetivos, entre eles a análise de possíveis deslizamentos em um determinado espaço geográfico. Modelos geomorfológicos determinísticos, em particular, apresentam algumas limitações com relação ao universo de conhecimento dos especialistas. Um modelo determinístico não necessariamente deve ser completo (não apresentando obrigatoriamente todos os parâmetros necessários para a solução ótima da saída), onde a precisão do modelo está relacionada com as variáveis que são utilizadas e a correta configuração da equação em si.

O SHALSTAB, utilizado nesse artigo, é um modelo matemático geomorfológico determinístico, bastante difundido por parte dos estudos geomorfológicos e com precisão razoável, que tem como objetivo apresentar locais em um espaço geográfico onde podem ocorrer os deslizamentos rasos, sendo possível prever um valor para a chuva crítica deflagradora da ruptura do solo (Ramos, et al. 2002).

$$
\frac{Q}{T}=\frac{\operatorname{sen} \theta}{(a / b)}\left[\frac{\rho_{s}}{\rho_{w}}\left(1-\frac{\tan \theta}{\tan \phi}\right)\right]
$$

\section{Equação 1. Modelo Matemático SHALSTAB}

O modelo SHALSTAB, retratado na equação 1, utiliza como parâmetros o índice de chuva crítica para ruptura do solo (Q), a transmissividade do solo (T), a densidade da água (@w), a densidade do solo úmido (@s), a área de contribuição por comprimento de contorno $(\mathrm{a} / \mathrm{b})$, o ângulo de inclinação da encosta $(\theta)$ e o ângulo de atrito interno $(\phi) . \mathrm{O} \log (\mathrm{Q} / \mathrm{T})$ representa o índice de estabilidade do solo, que quando maior que -2,2 indica uma região estável, e quando menor representa uma situação com diferentes graus de instabilidade (Ramos, et al. 2002).

\section{Módulo de Sensores}

O módulo de sensores é composto pelos sensores adequados para medição dos parâmetros requeridos pelo modelo matemático utilizado, bem como de microcontroladores para processamento dos dados e envio das medições para o servidor web.

Para realizar essa medição, foram utilizados alguns sensores próprios como o sensor ultrassônico, capaz de medir o nível da água, o acelerômetro, que percebe vibrações e movimentações do solo e o de umidade do solo (soil moisture sensor). Estes sensores estão ligados a um dispositivo integrado de microcontroladores, com um dispositivo Arduino e um Raspberry $\mathrm{Pi}$, juntos em um único modulo, em uma arquitetura onde o Arduino faz a leitura e controle dos sensores e dispositivos conectados a ele, retornando quaisquer valores medidos ao Raspberry $\mathrm{Pi}$, que com conexão à Internet pode enviá-lo a algum servidor ou outro dispositivo. Com essa 
proposta, o Arduino nas portas digitais tem conectado o sensor ultrassônico, e nas portas analógicas o acelerômetro e o sensor de umidade, fazendo a constante medição, conversão de grandezas e envio dos dados ao Raspberry Pi, e este tem a função de consolidar as informações a aplicar no modelo matemático SHALSTAB, o qual realiza o estudo dos dados (medidos pelos sensores) e determina a probabilidade de ocorrer um desastre natural na região de onde as medições se originaram. O Raspberry Pi também administra a conexão com a Internet que é feita por um modem de conexão 3G/4G. Desta forma, todas as informações medidas pelos sensores são enviadas para um servidor remoto e armazenadas em uma base de dados.

É importante ressaltar que esta arquitetura permite paralelismo entre a leitura dos dados do sensor (Arduino) e a execução dos cálculos e envio ao servidor web (Raspberry Pi), evitando assim que dados medidos pelos sensores sejam perdidos enquanto o dispositivo está ocupado com operações de cálculo ou envio à Internet.

\section{Implementação}

A arquitetura do sistema se baseia em três pilares principais: o módulo de sensores, que realiza as medições da região monitorada e os cálculos do modelo matemático; o servidor, responsável por armazenar os dados em uma banco de dados e disponibilizar a interface de monitoramento para a análise de um especialista; e o aplicativo móvel, que exibe as condições da região ao usuário e o notifica quando estiver em perigo, exibindo rotas de fuga de acordo com a indicação do especialista, da central de monitoramento.

Para o módulo de sensores foram utilizadas as funcionalidades dos microcontroladores Arduino e Raspberry Pi, junto com um conjunto de sensores. O Arduino, responsável pela integração dos sensores, é ligado ao Raspberry $\mathrm{Pi}$, responsável pelo modelo matemático e envio das informações ao servidor remoto (figura 1).

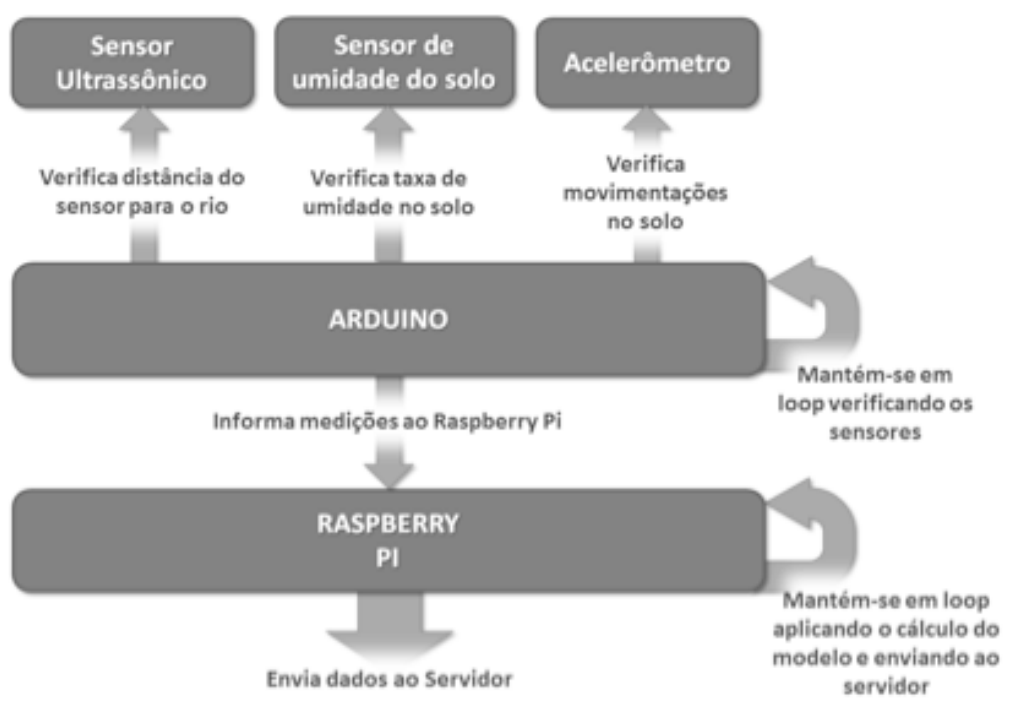

Figura 1. Funcionamento do Módulo de Sensores 
O servidor é composto pela interface do operador do centro de monitoramento de emergências, dois webservices de comunicação, um para o aplicativo e outro para o módulo de sensores, e o banco de dados, como ilustrado na Figura 2.

Os webservices de comunicação são responsáveis por salvar as medições dos módulos de sensores enviadas, e fornecer aos aplicativos nos dispositivos móveis as informações a respeito da posição em que estão localizados, incluindo locais de fuga caso a região esteja em perigo; implementados em $P H P$, recebem requisições HTTP dos módulos de sensores, salvando as medições em banco SQL Server, e dos aplicativos, fornecendo ao mesmo a partir da base de dados as condições da região.

Com a interface de monitoramento, é possível que um especialista na central possa analisar a condição das regiões e alertar a população se percebido algum perigo, definindo locais seguros para evacuação. A interface foi desenvolvida em ASPX e HTML5 e diversos códigos javascript, possibilitando a exibição de uma página dinâmica, em constante atualização com as medições e condições das regiões monitoradas.

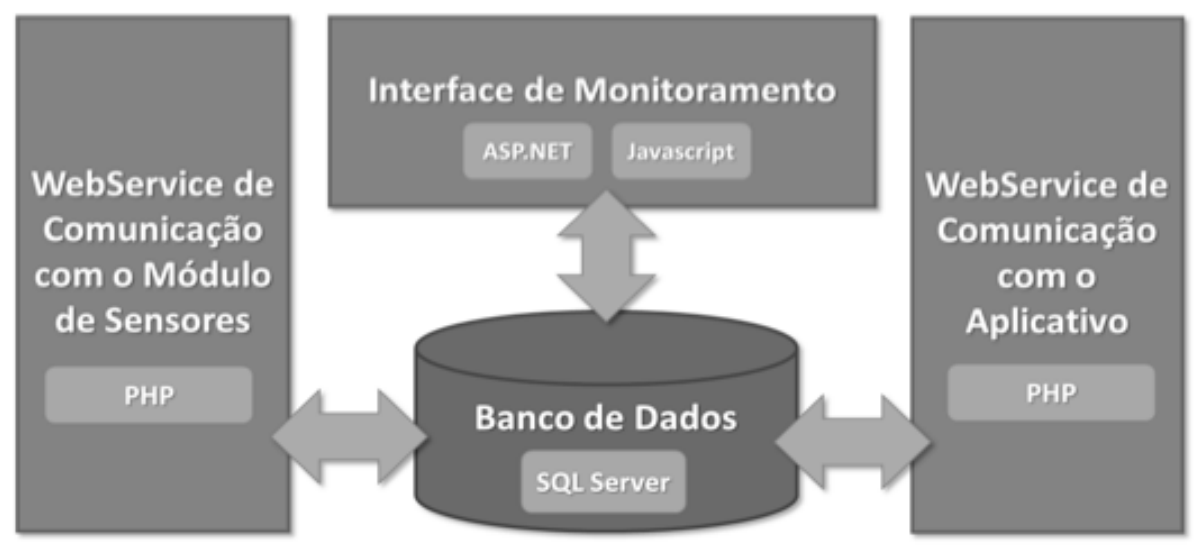

Figura 2. Arquitetura básica do servidor de monitoramento
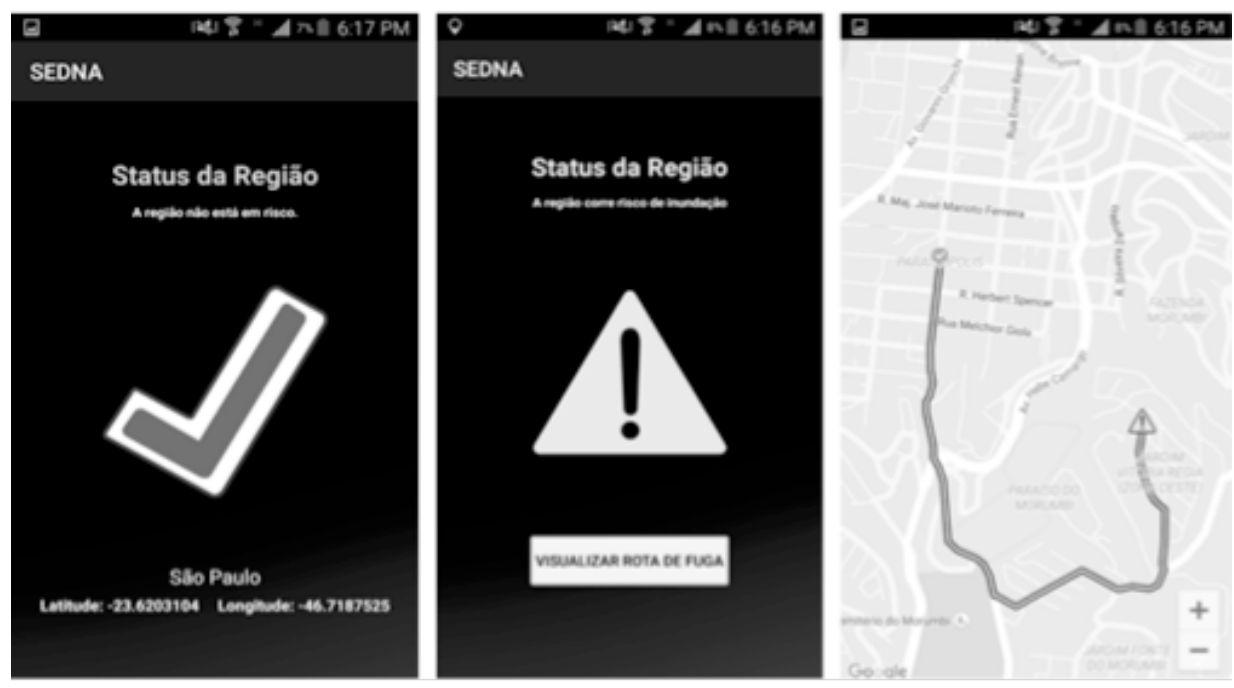

Figura 3. Telas do Aplicativo 
O aplicativo móvel destinado a smartphones (figura 3) é o elemento do sistema que possibilitará a população em risco ser notificada. Desenvolvido para a plataforma Android, em Java, é utilizado o recurso de GPS dos smartphones para obter a posição do usuário e enviado constantemente requisições HTTP ao servidor solicitando as condições naquela localização; caso a região esteja em risco, também receberá indicações de locais seguros, onde através da API do Google Maps, integrada com o sistema Android, exibirá um mapa com a rota para evacuação. Também há um processo em background em execução, onde sempre que a região se encontrar em perigo o aplicativo abrirá e um som de alerta será disparado.

\section{Resultados}

Para a realização dos testes foi desenvolvido uma maquete representando uma situação real de região de risco, detalhada na seção 5.1. A solução do sistema emergencial teve resultados satisfatórios e seus dois modos, para deslizamento e inundação. Dois resultados relevantes devem ser destacados. $\mathrm{O}$ primeiro diz respeito quanto à reação do sistema para diferentes valores enviados pelos sensores. Sempre que o nível pluviométrico ou o índice de estabilidade apresentam valores considerados perigosos, $\mathrm{o}$ sistema reage adequadamente e a interface de monitoração mostra apropriadamente o risco na região em que o sensor está posicionado. O segundo diz respeito às medições dos sensores e resultado dos modelos calculados em relação ao risco real naquela região; os testes mostram que os resultados dos cálculos efetivamente indicam o risco antes do desastre ocorrer, sendo possível realizar a evacuação.

\subsection{Maquete para testes}

Para realização dos testes e verificação da metodologia aplicada, foi desenvolvido uma maquete para simulação dos desastres de inundação e deslizamento de terra (figura 4). A maquete representa uma área em torno de uma cidade paulista, onde há um rio em frente de um prédio que representa um risco de inundação, e mais a frente um morro com alta inclinação (45 graus), representando um perigo de deslizamento.

A maquete possui uma base onde estão todos os componentes eletrônicos (o módulos de sensores), e alguns orifícios por onde os fios dos sensores passam e são posicionados na montanha e próximo ao rio; nessa base também há um reservatório de água com bombas submersíveis, que através de mangueiras podem encher o rio, umedecer o solo do morro por baixo e irrigar o solo por cima em uma espécie de chuva, através de furos na mangueira. Assim, é possível simular a situação dos dois desastres em escala, e verificar o funcionamento do sistema desenvolvido.

Para os testes foram preparadas amostras de solo típicas de uma região da cidade estudada; o solo foi preparado a partir de uma mistura de solo siltoso (entre areia e argila, possuindo partículas pequenas e corpo rígido), adequado para a simulação de deslizamento, menos rígido que o solo argiloso, mas mais coeso que o puramente siltoso. Dados como coesão e peso específico do solo foram medidos para configuração correta do módulo de sensor, com os parâmetros necessários para realização dos cálculos do modelo. É importante ressaltar que a configuração exata do solo da região não foi mapeada para a maquete, limitando-se apenas à inclinação e ao tipo de solo (siltoso), representativos de um risco de deslizamento. 


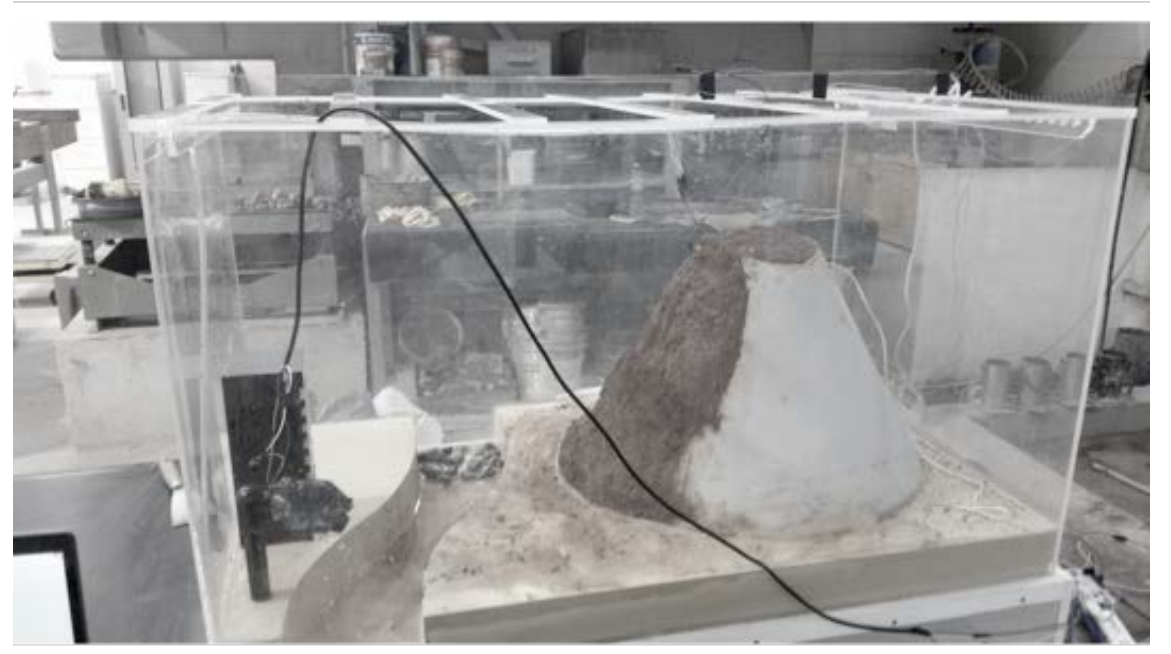

Figura 4. Imagem da maquete, com a mistura de solo aplicada e sensores posicionados

\subsection{Testes de deslizamento}

O primeiro teste foi realizado utilizando os parâmetros constantes da maquete, como a inclinação da encosta, porém simulando os dados medidos pelos dos sensores, como indicado na Figura 5.

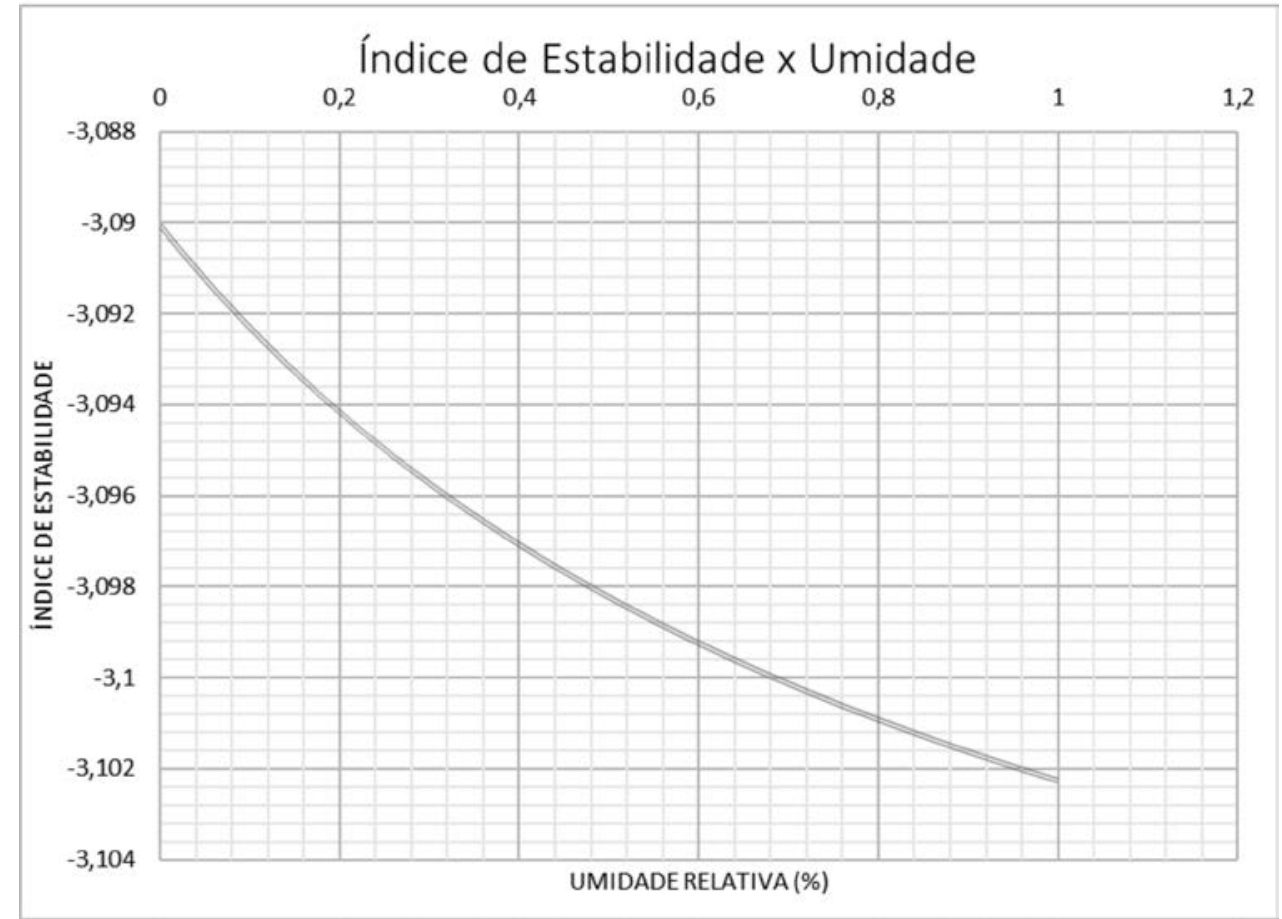

Figura 5. Gráfico do Índice de Estabilidade x Umidade

Utilizando o modelo matemático SHALSTAB e parâmetros pré-estabelecidos, verificou-se a reação do sistema. Conforme a umidade variou de 0 a 1 (0\% a 100\%), o resultado calculado pelo modelo matemático também mudou, indicando maior risco 
conforme a umidade aumentava, e o sistema corretamente reagiu à variação, mudando a cor da região na interface e indicando que estava em perigo.

De acordo com o modelo SHALSTAB, os resultados do modelo de estabilidade indicam o seguinte grau de instabilidade para os intervalos calculados, com risco variando de 1 a 7 :

- Índice de risco 1 , região incondicionalmente estável

- Maior que -2,2: Índice de risco 2 - região medianamente estável

- Entre -2,2 e -2,5: Índice de risco 3 - região pouco estável

- Entre -2,5 e -2,8: Índice de risco 4 - região pouco instável

- Entre -2,8 e -3,1: Índice de risco 5 - região medianamente instável

- Menor que -3,1: Índice de risco 6 - região muito instável

- Índice de risco 7, região incondicionalmente instável

Assim, para os resultados obtidos no gráfico, com umidade de $0 \%$ a região tem índice de risco 5, aumenta gradualmente e quando se torna 0,7 , o índice passa a ser 6 . É importante ressaltar que estamos considerando uma região de que já é de risco, devido sua alta inclinação. Cada região monitorada pode possuir parâmetros diferentes, onde a umidade influencia mais ou menos e a variação do índice de risco é diferente.

Posteriormente os testes de deslizamento foram realizados na maquete, com o solo adequado para tais experimentos, em uma superfície com ângulo de inclinação de $45^{\circ}$. No decorrer dos testes foram utilizados dois sistemas para umedecer o solo e causar o deslizamento: o sistema de infiltração por dentro da maquete e o sistema de mangueiras para simular a chuva. Os testes mostraram que com os cálculos do modelo é possível perceber o alto risco de deslizamento algum tempo antes do desastre ocorrer, possibilitando a evacuação.

Em um dos testes, os sistemas de infiltração e chuvas foram ligados (instante $x$ ), com o solo apresentado a umidade inicial de $65 \%$. Decorridos dois minutos e cinquenta segundos $(x+2: 50 \mathrm{~min})$, o nível de risco subiu para 6, o que já representa um alto risco de deslizamento conforme detalhado acima, e após mais um minuto e doze segundos $(x+4: 02 \mathrm{~min})$ o deslizamento ocorreu. Antes de ocorrer, quando o índice subiu para 6, foi enviado através da interface de monitoramento um alerta aos usuários na região, exibido corretamente no aplicativo. No teste verificou-se o funcionamento da comunicação fima-fim, desde a medição dos sensores até o alerta ao usuário, bem como a validade do modelo SHALSTAB para os valores de umidade medidos, mostrando que a região se encontrava em risco 1 minuto e 12 segundos antes do desastre ocorrer, permitindo a evacuação. A figura 6 mostra a variação das medições de umidade em função do tempo, do instante inicial de testes (0 seg) até o final (241 seg), e a figura 7 mostra como o índice de risco, como definido acima, variou nesse mesmo período.

Vale ressaltar que o tempo do instante em que o risco subiu para 6 até o momento em que o deslizamento iniciou foi curto, propositalmente, pois o cenário montado já era classificado como uma área de risco, devido sua alta inclinação e a mistura de solo preparada, processo acelerado pela entrada de água por diversos pontos em todo o sistema, com alta vazão, que pode representar uma situação real de chuva 
muio intensa, de forma proposital a causar rapidamente a ocorrência do evento de deslizamento. $\mathrm{O}$ especialista pode analisar e julgar se a região está em risco ou não de acordo com os cálculos do modelo e a umidade que vai aumentando, e realizar o alerta aos usuários se necessário. Assim, não há um índice de risco em específico em que se pode afirmar com certeza que o desastre ocorrerá; essa é uma decisão passível de julgamento humano.

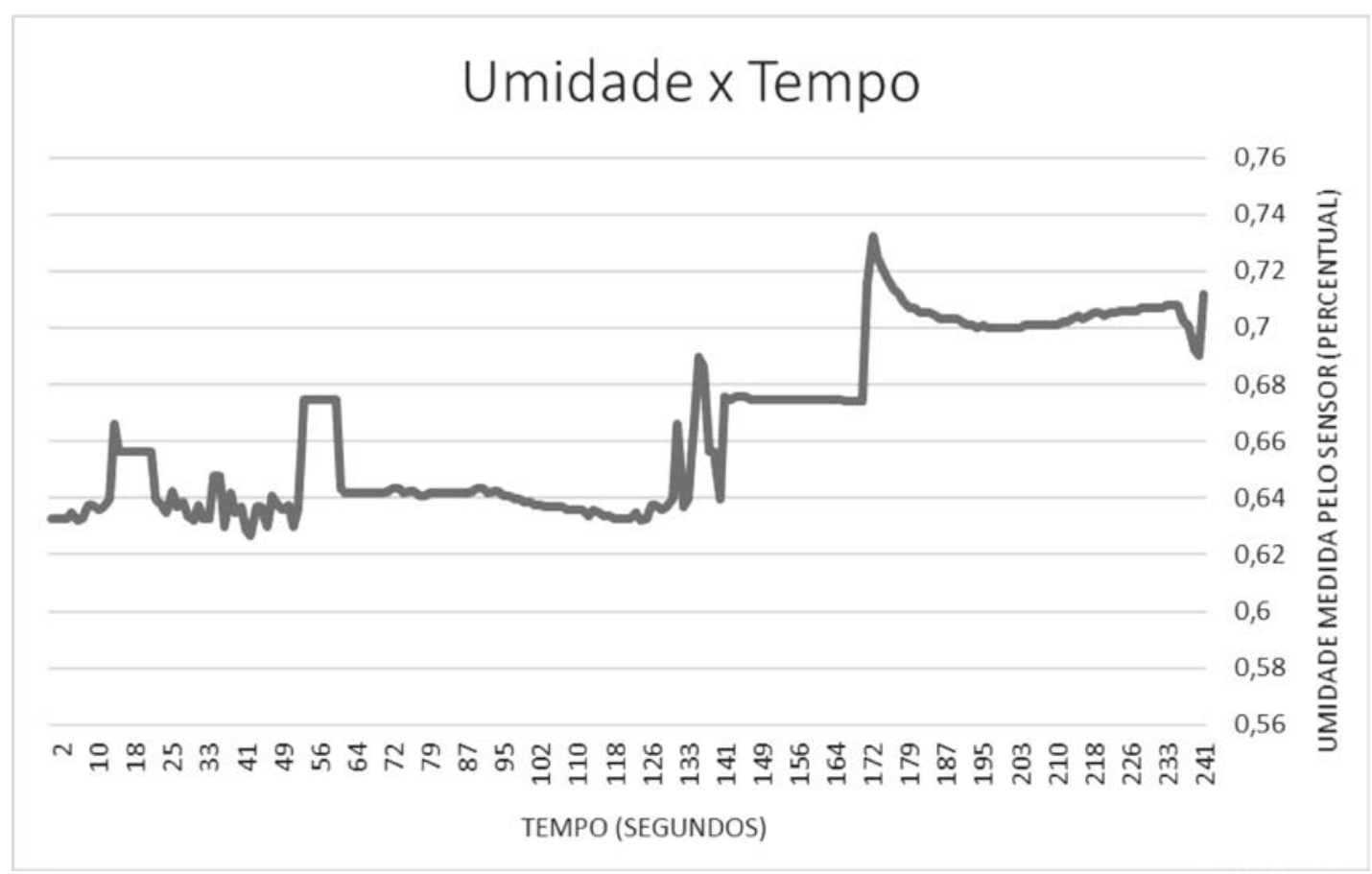

Figura 6. Gráfico da Umidade do Solo x Tempo

$$
\text { Índice de Risco x Tempo }
$$




\subsection{Testes de Inundação}

Os testes simulados mostraram que o sistema reage corretamente aos valores do índice pluviométrico medido. O índice é calculado com base na profundidade do rio, e o nível de água presente, sendo um valor percentual do quanto o mesmo está cheio. A partir de testes empíricos, os seguintes intervalos foram definidos:

•Índice de 0 a 0,5: Região segura

-Índice de 0,5 a 0,75: Região em alerta

•Índice superior a 0,75: Região em risco

Definindo o intervalo dessa forma, é possível manter a central de monitoramento atenta às regiões em alerta, passíveis de inundações, porém ainda não em risco, onde com nível superior a 75\% a central de monitoramento será alertada, e de acordo com o seu julgamento o alerta poderá ser emitido. É importante perceber que tais intervalos devem ser estabelecidos pela autoridade de monitoramento, analisando e definindo o risco em que a região se encontrará para diferentes índices pluviométricos. Para a maquete apresentada o sistema respondeu adequadamente, indicando o risco conforme o nível pluviométrico subiu.

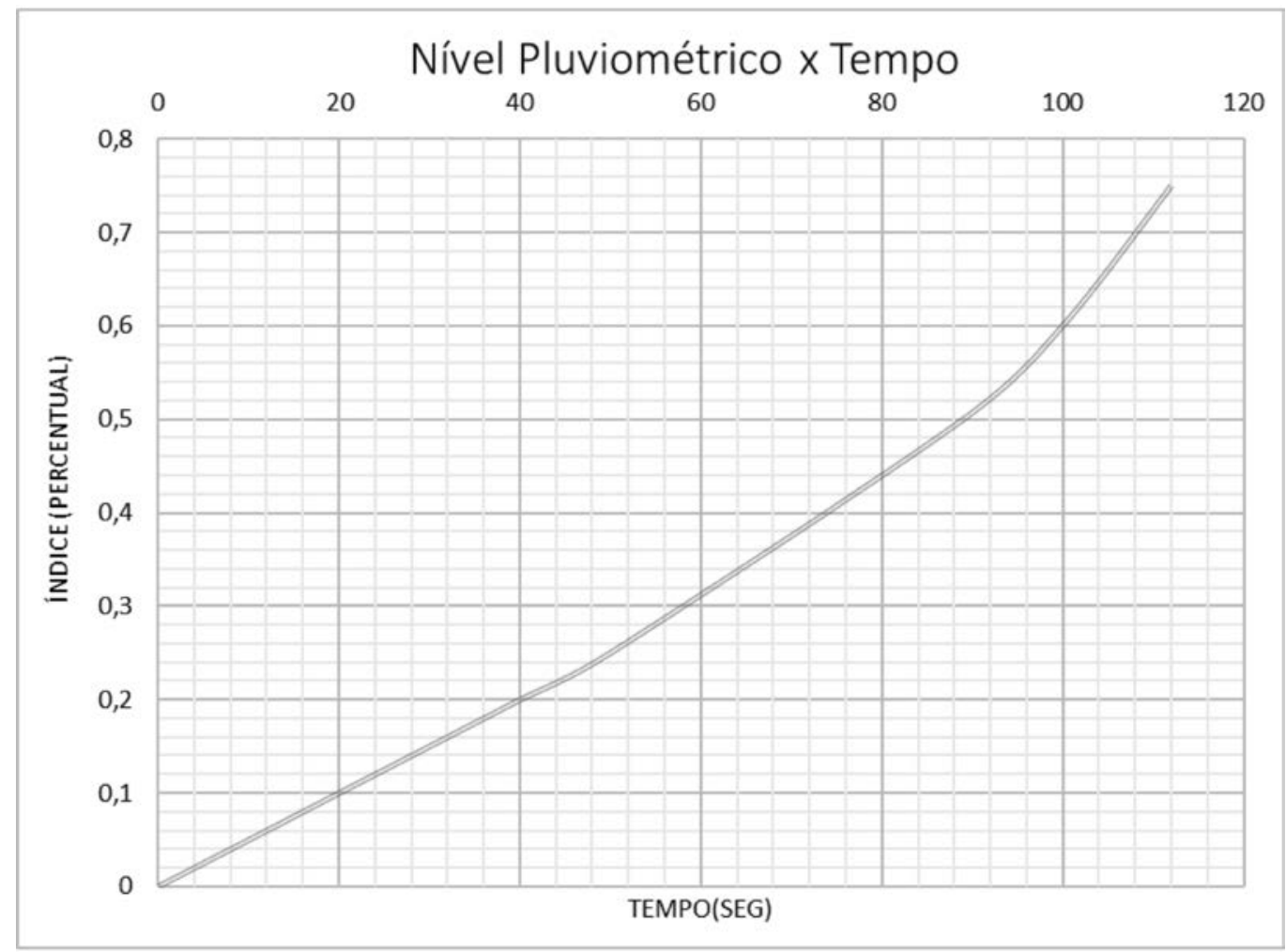

Figura 8. Gráfico do Nível Pluviométrico x Tempo

Testes realizados de inundação foram realizados na maquete, no local criado para tal experimento. A profundidade do rio é de $6,5 \mathrm{~cm}$ e a altura do sensor ultrassônico é de 14,2cm. Assim, com o sensor medindo uma distância de $14,2 \mathrm{~cm}$, se conclui que o nível de água é 0 , e o índice pluviométrico, portanto é de $0 \%$. A partir desse nível do rio, a bomba foi ligada para a entrada de água; após o período de aproximadamente 1 minuto e 29 segundos, o sistema indicou a região como em alerta, com um índice 
pluviométrico em $50 \%$, e em 1 minuto e 52 segundos a região entrou em risco de inundação, representando $75 \%$ do rio cheio, com um crescente aumento, sendo assim necessário ao operador emitir um alerta aos usuários; esse teste está representado no gráfico da figura 8 . O sistema reagiu corretamente ao aumento do nível, onde verificouse a eficácia do sistema no monitoramento do desastre. O tempo adequado para evacuação deve ser definido pela autoridade responsável, onde os intervalos de risco para os níveis do rio devem ser ajustados de forma a indicar a situação perigosa com a antecedência desejada.

\section{Considerações Finais}

Com base nos resultados observados através da implementação do sistema e testes com a maquete, é possível concluir que o sistema consegue atender as necessidades e os objetivos previamente estipulados com relação a efetividade de evacuação de regiões de risco.

Nos testes realizados em laboratório o sistema consegue monitorar o estado atual do solo e indicar possíveis riscos com antecedência à ocorrência do evento, para a central de monitoramento, responsável por emitir o alerta e evacuar a região através do aplicativo para smartphones.

Em termos de implementação e adoção do sistema em larga escala, é importante perceber que em relação ao monitoramento de inundações são necessárias poucas alterações no modelo utilizado para garantir o funcionamento em qualquer tipo de margem de rio, lago ou córrego. Para desastres como deslizamento de terra, o sistema computacional funciona, porém com algumas limitações: a necessidade de um mapeamento prévio do solo e a adaptação do modelo matemático para cada local de implantação. Portanto, o modelo nem sempre deve ser aplicado indiscriminadamente para qualquer região.

O sistema foi testado e validado somente com um único módulo de sensores, através do desenvolvimento da maquete. Para o monitoramento de uma região real, é importante que sejam utilizados diversos módulos para obtenção das condições em diferentes pontos da encosta e do rio e a utilização de técnicas de redes de sensores para um processamento central no servidor e agregação dos dados, permitindo a análise da situação geral de toda a região, e não de somente alguns pontos.

Pode-se concluir que o sistema desenvolvido é aplicável em cenários reais de forma com que o sistema como um todo (sensores, interface de monitoramento e aplicativo), com os ajustes necessários, garanta uma otimização do tempo para evacuação das pessoas em uma região, evitando assim a perda de vidas.

\section{Agradecimentos}

Os autores agradecem ao Laboratório de Inovação em IoT FEI Telefônica Vivo pelo apoio financeiro à pesquisa e pela parceria Universidade - Empresa; convênio TA004/14. 


\section{Referências}

Brito, G. (2013) "Modelo de Monitoramento de Deslizamento de Encostas Por Meio de Sensor Multiparamétrico", Dissertação (Pós-graduação em Desenvolvimento em Processos Ambientais) - Universidade Católica de Pernambuco, Recife.

Collins, T. (2004) "Disaster Risk for Floods: 1980 - 2000”, United Nations University. Tokyo: 2004. p.6. 56 f., http://www.unu.edu/news/ehs/floods.doc , 29 março 2016

Gomide, R. (2013) "Só 10\% dos moradores atendem a sirenes de evacuação em áreas de risco do Rio". Último Segundo, Rio de Janeiro, 17/01/2013. http://ultimosegundo.ig.com.br/brasil/rj/2013-01-17/so-10-dos-moradores-atendema-sirenes-de-evacuacao-em-areas-de-risco-do-rio.html, 29 março 2016.

Nelson, F. F., Guimarães, R. A., Montgomery, D. (2001), "Condicionantes Geomorfológicos dos Deslizamentos nas Encostas: Avaliação de Metodologias e Aplicação de Modelo de Previsão de Áreas Susceptíveis". Revista Brasileira de Geomorfologia, Rio de Janeiro, v. 2, 2001, http://repositorio.unb.br/bitstream/10482/15860/1/ARTIGO_CondicionantesGeomor fologicosDeslizamentos.pdf, 29 março 2016.

Nullis, C. (2014), "Atlas de Mortalidades e Perdas Econômicas por fatores de Clima e Desastres Naturais". Organização Meteorológica Mundial (OMM), Geneva, n. 998, $11 \quad J u l h o \quad 2014$. https://www.wmo.int/pages/mediacentre/press_releases/pr_998_en.html, 29 março 2016.

Ramos, V. M., et al. (2002) "Aplicação do Modelo Shalstab, em ambiente Arcview, para o mapeamento de áreas susceptíveis a escorregamento raso na região do quadrilátero ferrífero (MG)". Espaço \& Geografia, v. 5, 2002. Disponível em: http://repositorio.unb.br/bitstream/10482/10656/1/ARTIGO_AplicacaoModeloShalst ab.pdf, 29 março 2016

Terzis, A. (2006) "Slip Surface Localization in Wireless Sensor Networks for Landslide Prediction”, http://www.cs.jhu.edu/ terzis/landslide-camera.pdf, 29 março 2016 